\title{
MOLECULAR PHYLOGENETICS AND GENERIC CONCEPTS IN THE MAXILLARIEAE (ORCHIDACEAE)
}

\author{
Norris H. WiLliams ${ }^{1} \&$ W. Mark WhitTen \\ University of Florida, Florida Museum of Natural History. Gainesville FL 32611-7800. USA. \\ orchid@flmnh.ufl.edu・whitten@flmnh.ufl.edu \\ ${ }^{1}$ Author for correspondence
}

Tribe Maxillarieae account for approximately 10\% (>2800 species) of Orchidaceae and are a major component of the Neotropical epiphytic flora. Pollination systems include 1) male euglossine-bee fragrance rewards in four subtribes, 2) oil reward systems and mimicry in some groups, 3) nectar rewards in a wide range of taxa, and 4) pseudocopulation in some Maxillariinae and some Oncidiinae. Generic and subtribal limits have been chaotic. Current, ongoing taxonomic treatments offer little hope of stability unless the revisions are based upon well-sampled molecular and morphological cladograms. Several classically defined genera are widely recognized as being polyphyletic. Our delimitations of subtribes and genera in these advanced Neotropical groups are based on well supported cladograms from combined analyses of nuclear (ITS) and plastid (matK, trnL-F intron-spacer, and the $a t p B-r b c L$ intergenic spacer) sequences.

We recognize subtribes Coeliopsidinae, Maxillariinae, Oncidiinae, Stanhopeinae, Zygopetalinae, and a monotypic Eriopsidinae sister to these other subtribes. Subtribes Coeliopsidinae and Stanhopeinae are pollinated exclusively by male euglossine bees utilizing many different sites for pollinarium placement; the molecular phylogeny agrees closely with traditional generic limits based on morphology. Maxillariinae, Oncidiinae, and Zygopetalinae have a variety of pollination systems and classifications based on floral morphology disagree with molecular phylogenies, probably because of convergence to pollination-related floral characters. Oncidiinae are one of the most diverse groups in the Orchidaceae in terms of floral diversity and pollination biology, chromosomal numbers, and vegetative morphology. The subtribe has more than 1,000 species (possibly as many as 1,800 species) distributed in over 75 currently recognized genera.
In the Oncidiinae we have sequenced 545 species representing 84 generic concepts for one sequence (ITS) and 240 species for two additional sequences (matK and $\operatorname{trnL}$ ). We have also sequenced 114 taxa for the $a t p B-r b c L$ intergenic spacer. We investigated the usefulness of elongation factor 1-alpha as a potentially useful region for species level questions, but it appears to be a gene family and while it might be useful in understanding intrageneric relationships, it proved to be not useful at the generic level. The external transcribed spacers of Tolumnia and Erycina were amplified with $26 \mathrm{~S}$ and $18 \mathrm{~S}$ primers, followed by cloning of the PCR products and sequencing with the $18 \mathrm{~S}$ primer (reverse). Technically, the sequences are good, but the variation is too great for alignment at the interspecific level. ETS may be useful at intraspecific levels in Tolumnia, but more work is needed.

The formerly recognized subtribes Lockhartiinae, Pachyphyllinae, Ornithocephaline, and Telipogoninae are all embedded in the Oncidiinae and form a well supported clade.

We have done combined analyses of a four region matrix for the Oncidium/Odontoglossum complex, and find that by using all four regions combined the support and resolution is greatly increased.

The results confirm the non-monophyletic nature of Oncidium and suggest Chamaeleorchis, Cochlioda, Collarestuartense, Mexicoa, Miltonioides, Odontoglossum, Sigmatostalix, Solenidiopsis, and Symphyglossum could be merged into Oncidium. However, more extensive work on ITS in this group shows several clades in the Oncidium/Odontoglossum group:

1. a broad Oncidium, including Miltonioides, Mexicoa, Sigmatostalix, one species of Odontoglossum, and the majority of Oncidium species sampled so far; 
2. the Oncidium obryzatum (correctly Oncidium. klotzschianum Rchb.f.) group of three species;

3. Cochlioda, Solenidiopsis and closely related species of the Odontoglossum multistellare group (= Collarestuartense);

4. two broad Odontoglossum groups of species groups, including Symphyglossum and the majority of Odontoglossum species sampled so far;

5. a one species clade of Odontoglossum povedanum;

6. a two species clade of an undescribed species from Panama (provisionally called Oncidium zelenkoanum) and Oncidium obryzatoides;

7. a clade of the Oncidium fuscatum alliance of six species of Oncidium (= Chamaeleorchis Senghas \& Lückel);

8. a clade of the Oncidium cheirophorum/Oncidium ornithorrhynchum group of species;

9. the clade of the Oncidium heteranthum group of species; and

10.Oncidium excavatum, an anomalous species in many respects.

The combined plastid and nuclear data show the best resolution into recognizable groups, although even this demonstrates the necessity of completing the data matrix and filling in missing clades from the larger 545 taxon ITS only matrix. At this stage we foresee the following possibilities: a core Oncidium (including Mexicoa and Miltonioides); Sigmatostalix; a new genus for the Oncidium zelenkoanum clade; recognizing Collarestuartense for the Odontoglossum multistellare clade; a core of two groups in Odontoglossum (including Symphyglossum); the Oncidium fuscatum clade (Chamaeleorchis); a new genus for the Oncidium cheirophorum clade; a new genus for the Oncidium heteranthum group; and probably a monotypic genus for Oncidium excavatum.

Based on well supported cladograms, we have made numerous taxonomic changes: 1) the 'mule-ear' (Lophiaris) and 'rat-tail' (Cohniella) oncidiums were transferred into Trichocentrum; 2) Psygmorchis and Oncidium crista-galli were transferred to Erycina; 3) Oncidium section Serpentia was transferred to Otoglossum; 4) Oncidium sect. Cucullata was transferred to Caucaea; 5) Cyrtochilum was redefined to include Dasyglossum, Neodryas, Rusbyella, and Trigonochilum and is distinct from the core group of Oncidium; 6) Anneliesia was included in Miltonia; 7) Tolumnia includes Braasiella, Gudrunia, Hispaniella, and Olgasis. On the basis of molecular data for four sequence regions we have segregated three new genera from Oncidium: Chelyorchis, Cyrtochiloides, and Zelenkoa for species previously included in Oncidium.

With the results we have to date, we feel more comfortable segregating several clades as distinct genera, rather than lumping everything into Oncidium. We feel that this approach will be accepted by the public and other workers rather than other possible courses of action.

Norris H. Williams, Ph.D., is Curator of Vascular Plants at the University of Florida, Florida Museum of Natural History Herbarium, and has worked on floral fragrances, pollination biology, and the systematics and evolution of orchids. He is currently spending most of his time on studies of the molecular systematics of Neotropical Orchidaceae.

W. Mark Whitten, Ph.D., is Senior Biologist at the University of Florida Herbarium and has worked on floral fragrances, pollination biology, and systematics and evolution of orchids. He is also currently spending most of his time on studies of the molecular systematics of Neotropical Orchidaceae. 